University at Albany, State University of New York

Scholars Archive

4-2012

\title{
Case Study: University at Albany Develops a Guide to Examine Commuting Behavior and Patterns
}

\author{
Catherine T. Lawson \\ University at Albany, State University of New York \\ Mary Ellen Mallia \\ University at Albany, State University of New York \\ Chris Franklin \\ University at Albany, State University of New York \\ Benjamin Fischer \\ University at Albany, State University of New York \\ David Hogenkamp \\ University at Albany, State University of New York
}

See next page for additional authors

Follow this and additional works at: https://scholarsarchive.library.albany.edu/sust_pubs

Part of the Environmental Studies Commons, Transportation Commons, and the Urban Studies and Planning Commons

\section{Recommended Citation}

Lawson, Catherine T.; Mallia, Mary Ellen; Franklin, Chris; Fischer, Benjamin; Hogenkamp, David; and Ryan, Matt, "Case Study: University at Albany Develops a Guide to Examine Commuting Behavior and Patterns" (2012). Publications. 1.

https://scholarsarchive.library.albany.edu/sust_pubs/1

This Article is brought to you for free and open access by the Scholarship at Scholars Archive. It has been accepted for inclusion in Publications by an authorized administrator of Scholars Archive. For more information, please contact scholarsarchive@albany.edu. 
Authors

Catherine T. Lawson, Mary Ellen Mallia, Chris Franklin, Benjamin Fischer, David Hogenkamp, and Matt Ryan 


\title{
Case Study: University at Albany Develops a Guide to Examine Commuting Behavior and Patterns
}

\author{
Catherine T. Lawson, Ph.D.' and Mary Ellen Mallia, Ph.D. ${ }^{2}$, principal investigators; and \\ Chris Franklin, Benjamin Fischer, David Hogenkamp, and Matt Ryan, student team members
}

\begin{abstract}
The University at Albany (SUNY) conducted a full examination of campus commuter patterns and behavior over an eighteen month period beginning in April of 2009. The main steps undertaken for this study include: reviewing existing options for alternatives to one-person per car commuting; developing Geographic Information Systems (GIS) maps of the commuting population's home locations; investigating the on-time performance of the main transit lines that serve the campus though Global Positioning Systems (GPS), conducting a survey of commuting behaviors, and convening focus group discussions. The study revealed that the success of alternative transportation is hindered by limitations in bus routes and frequency in scheduling, the need for commuters to make additional trips outside their commute route, and a distrust of bus reliability during high stress periods (i.e., exams). Cost factors were found to have a larger influence on student demand for using automobiles while convenience was reported as the largest issue for the employees.
\end{abstract}

The University at Albany, part of the larger State University of New York (SUNY) system, consists of four campuses: the main campus and nanotech campus are adjacently located in the uptown section of Albany, NY, the third is located two miles closer to the downtown area of the city, and the fourth is located in Rensselaer, NY. There are roughly 4,000 faculty and staff at the university and approximately 18,000 students; 7,500 students live on campus.

\section{Introduction}

Calculations of the carbon footprint at University at Albany revealed that more than $20 \%$ of direct $\mathrm{CO}_{2}$ emissions result from commuting activities. Furthermore, while the university accurately measures energy use in order to devise comprehensive conservation and efficiency strategies, the same was not true for commuting patterns. Therefore, in an effort to decrease greenhouse gas emissions and develop a model for other universities to follow, the University at Albany Offices of Environmental Sustainability, Institutional Research and Planning, and Parking and Mass Transit worked with the Geography and Planning Department, to undertake an intensive examination of its commuter patterns and behavior. This led to recommending several transportationdemand management strategies designed to increase the use of alternative and shared transportation. In addition, an open access handbook was developed to enable replication of the procedures in other locations and larger reductions in carbon footprints as fewer vehicles are used for commuting. This handbook, available online, describes in detail the procedures and the Arc GIS software used by the university to map commuter travel patterns and track bus on-time performance; it also includes a copy of a campus survey and focus group questions.

'Assistant Professor of Geography and Planning and Director of the Master's in Urban Planning program ${ }^{4}$ Civil, Environmental and Geomatic Engineering, ${ }^{5}$ Director of Environmental Sustainability 


\section{Step 1: Overview of Alternatives}

Addressing the methods of commuter transportation is a vital part of achieving carbon reductions. However, there are often institutional constraints to tapping into the potential for reaching such goals, which can be seen in the lack of awareness of the relationship between commuting and carbon reductions as well as availability of feasible solutions. The first step in the analysis is to research all existing options for alternative transportation for commuters of an institution and make that knowledge available to the campus community. Although this process is undertaken at many colleges and universities, disseminating the information to the commuters can prove difficult.

At the University at Albany, several existing transportation options were found to be available for commuters-university and city bus transit lines, park-and-ride lots, and a carpool service. The carpool service is part of a regional carpooling service provided by the local metropolitan transit organization which the university joined in fall of 2008 . As a participant in the regional service, the university could insert its own webpage on the website of the regional system, enabling members of the campus community to sign up for this service at no cost and search within the transit population for carpool matches. There are other commuter bus lines outside of the university system, either sponsored by a local government entity or an independent transportation company, but few have stops at the university or schedules that meet the needs of campus commuters. It was also discovered through the commuter survey that most commuters did not know where to go for information on mass transit and carpooling.

\section{Step 2: Map the Location of Commuters}

Knowing the starting location of the commuting population facilitates the formation of shared rides and communication about relevant alternative transportation options. Addresses obtained from parking permit applications can be entered into a Geographic Information Systems (GIS) program to generate maps; at the University at Albany, these maps proved extremely helpful in identifying clusters where commuters reside. The mass transit line routes were overlaid on the GIS maps so the review team could identify commuters who were on a particular bus line. This helped reveal the main obstacles for taking mass transit: the infrequency of the bus runs and the schedules of the bus routes didn't align with work and class schedules. In general, people had reasonable access to bus lines, physically, but bus schedules made it inconvenient to take the bus. Once the location of commuters has been mapped, they can be sent information specific to their mass transit optionsanother benefit of this kind of mapping.

\section{Step 3: On-time Performance of Current Mass Transit}

Reliability of mass transit is essential in getting consumers to use alternative transportation. The University at Albany decided to make use of a Global Positioning System (GPS) to determine whether campus mass transit is on time. These devices were employed on the main student bus transit lines to calculate an on-time percentage for each line and the frequency and degree of deviation from scheduled services. The bus routes were examined during the 2009 fall semester. Student volunteers from the Geography and Planning Department, rode 4 bus lines, two from the university fleet and two from the city's fleet over a six week period and logged in arrival and departure times in order to assess the on-time percentage of each route.

During the process of collecting on time data over the fall of 2009 there were several lessons learned, the most important of which relates to the GPS technology itself. Handheld GPS units were inefficient for determining on-time percentage and the process became very expensive and timeconsuming. A greatly improved outcome could come from using an automated vehicle location (AVL) system. AVLs would benefit all transit users as these systems track location in real-time and the application can be accessed via a smartphone or the Internet to determine when a bus will arrive at a stop. At the University at Albany, it was discovered that while the bus lines were relatively consistent in their schedule, they had numerous early departures from the bus stops, thus diminishing their reliability. As a result of this study, the university is implementing an AVL system to track how well the universityrun buses adhere to the published schedules.
Also, with an AVL system, Rose Anne Dorsman, director of parking and mass transit at University at Albany, and Michael Koch, transportation supervisor, will be able to access the departure data and investigate problems when anomalies occur. The process of using the AVLs will also establish accountability of the bus drivers in keeping to the listed schedule. Additionally, with the AVL system bus drivers will be able to communicate this to the mass transit office and a signal can be sent via the system to commuters that the bus is full. The office can then $\log$ in indicate if a bus is full, making known thus identifying the reason for an early departure. Thus, the university expects to have more insight into the reasons for early departures of the university bus fleet. It should be noted the city fleet is not adopting the same software for their buses.

\section{Step 4: Survey Commuters}

Getting data about the composition of the commuting population and their preferences can be attained through a comprehensive survey. This information can result in better marketing strategies to promote alternative transportation to commuters and can help calculate the carbon footprint of commuters to the university. Both an online survey and focus group discussions on commuting behaviors and preferences were conducted as part of this study. The data for the student and employee surveys show that driving is the dominant form of commuting (39\% daily-use students; $73 \%$ daily-use employees), mainly because people said it is more convenient, and, secondarily, they cited a need to add other stops to and from their commute to the university.

While students reported using the bus rather frequently, all other modes of alternative and shared transportation are far less commonly used. Specifically, $18 \%$ of the students reported using the university fleet on a daily basis, $26 \%$ use the metropolitan transit fleet, and $16 \%$ walk, $4 \%$ carpool, and $1 \%$ bike. For employees, $2 \%$ said they use the university fleet, $4 \%$ the metropolitan transit, while $3 \%$ walk, $6 \%$ carpool, and $1 \%$ bike. Both groups found major limitations in bus transit due to infrequency of service, length of trip, and unavailable routes. Carpooling was hindered by several factors. First, given the nature of university systems for faculty, a lack of social networking outside a specific department reduces a person's ability to find 

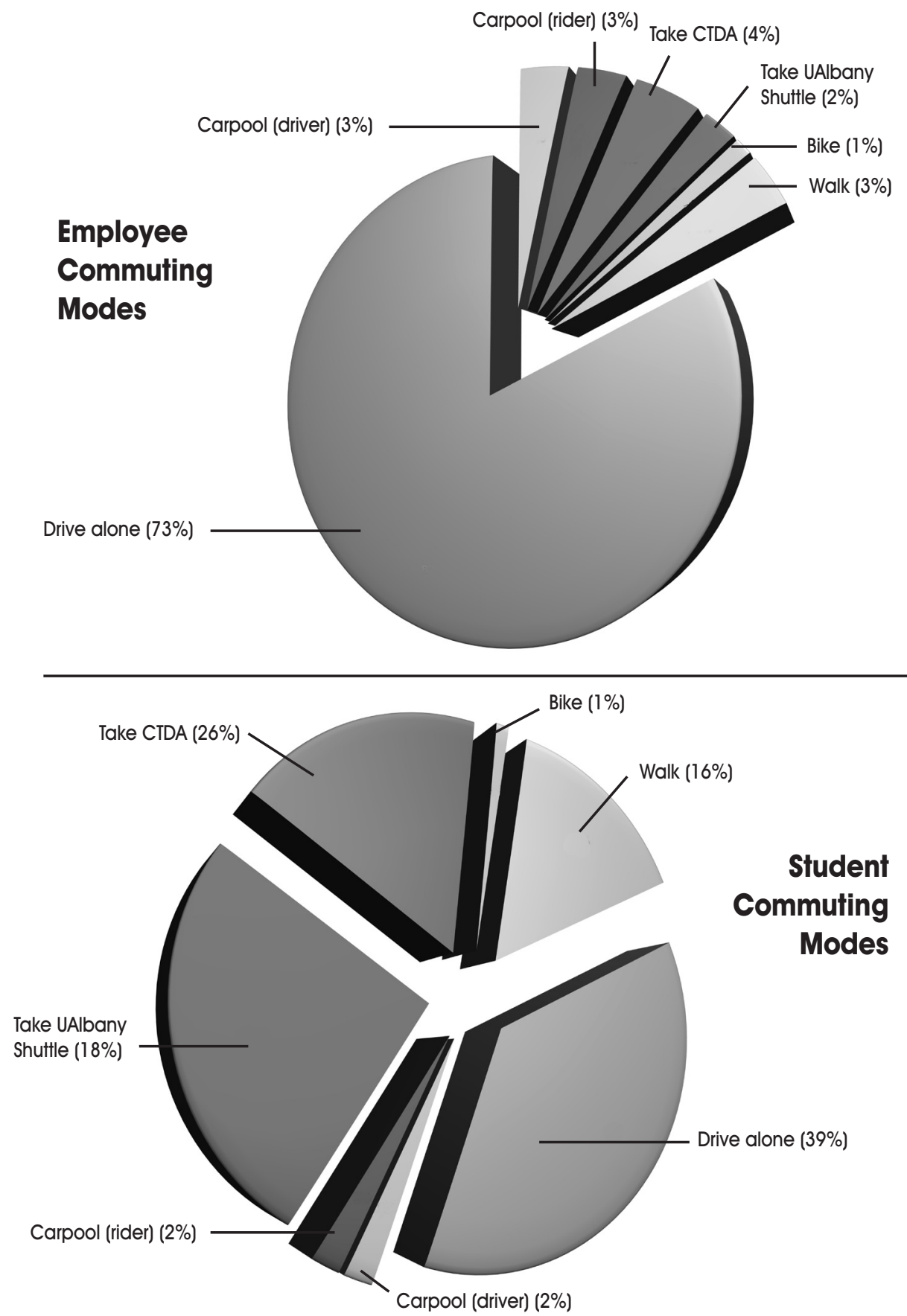

a carpool partner from another office or department. Second, there is often a social barrier to sharing a ride with someone who is relatively unknown. Third, given the size of the university, ensuring that information is disseminated to the entire campus has proven difficult. Despite several methods of communication, there are still people unaware of the carpooling service with only $21 \%$ of employees and $11 \%$ of students indicating that they knew where to get information on finding a carpool partner Bicycling suffered from safety concerns and walking was limited by the distance to campus from home.

Also, the data indicate that student and employee transportation choices could be influenced through different incentives. Students were most responsive to access to free buses (39\% definitely would use) and rewards for using alternative transportation (22\% definitely would use). Employees were more likely to agree to alter their work schedule if they could gain the ability to work from home (39\% definitely would use) or a compressed work week (29\% definitely would use).

While many institutions may use the survey tool, in this study it was found that the use of focus groups provided the researchers with more detailed responses, clearing up ambiguities from the survey results. Survey participants were given an opportunity to indicate whether they would be willing to take part in focus groups and the university then conducted six of these groups over a two-week period. Four focus groups consisted of students, one was comprised of faculty, and the last made of staff members. The student groups were further divided into the following categories: on-campus, offcampus undergraduate male, off-campus undergraduate female, and off-campus graduate students. The focus groups revealed additional reasons for not using alternative transportation that had not been identified in the survey, along with clarification on rewards that might entice usage.

For example, in this study, $27 \%$ of employees and $10 \%$ of students cited "other" as the reason for not using alternative forms of transportation. The focus groups were asked to address this issue and discuss transportation concerns, as well as engage in a more detailed discussion about other survey questions, for example: What kinds of rewards would motivate people? How can biking and walking be made safer? What other trips do you need to make to and from campus that hinder taking alternative transportation? Also reported during the course of the focus group meetings were general alternative transportation concerns, such as distrust of bus reliability during high stress periods, (i.e., exams), the value of having private time alone in a car, and potential solutions, such as parking lot shuttles, expanded on-campus daycare, graduate housing, and dormitoryled bus-education programs.

\section{Conclusion}

As a result of this study, the university has undertaken several initiatives. The first is the implementation of an AVL system on all campus buses, which will relay in real time the location of the buses to monitoring stations; the system will have a corresponding smartphone application that can access the data. The university now includes information about their carpooling service to the campus community through the annual 
car registration notification process. Commuters living within the same zip code were e-mailed information about the carpool service, the number of commuters in the same zip code, and the amount of money they could save by carpooling. Currently, the University is implementing an AVL system on all campus buses, which will relay in real time the location of the buses to monitoring stations; the system will have a corresponding smartphone application that can access the data. Finally, the campus transportation survey will be administered every three years to assess changes in commuting trends and behaviors with the next round to be conducted in this fall.

This study focused on the use of singleoccupancy vehicles by employee and student commuters at the University at Albany, but the techniques used to obtain the data can be applied to any college, university, or other large campus. A more efficient and better utilized alternative transportation system can be achieved through developing options, improving reliability, having easy access to important information, and fostering transportation partnerships. Achieving the goals can be aided by the technology described in this project, which is readily available and relatively inexpensive. Forming partnerships between transit authorities and institutions is also essential in capitalizing on collaboration possibilities. The process will not occur overnight and will require frequent reflection to determine if the right strategies are being implemented, but the rewards can be great in terms of reducing overall vehicle miles traveled and decreasing the carbon footprint on campus.
An open access handbook, providing a full description of the techniques used, tips for implementation, and copies of the survey can be accessed at: www.albany.edu/ gogreen/4.transportationstudy.shtml.

Address correspondence to:

Mary Ellen Mallia, Ph.D.

Director of Environmental Sustainability

University at Albany

University Hall 212

1400 Washington Avenue

Albany, NY 12222

E-mail: mmallia@albany.edu www.albany.edu/gogreen Facebook: UAlbany Green Scene 